\title{
Maker-Centered Project-Based Learning in Inclusive Classes: Supporting Students' Active Participation with Teacher-Directed Reflective Discussions
}

\author{
Kati Sormunen, et al. [full author details at the end of the article]
}

Received: 3 September 2018 / Accepted: 29 May 2019 / Published online: 18 June 2019

(C) The Author(s) 2019

\begin{abstract}
Supporting students' active participation in maker-centered project-based learning (PBL) can be challenging in inclusive classes. The aim of this study was to support students' active participation in cooperative team via teacher-directed reflective discussions during an inclusive, maker-centered PBL unit. The study was conducted during the students' final year of primary school. In the context of 44 students' inclusive class, the study focused on a team of 11 students ( 4 girls, 7 boys; aged $12-13$ years) who worked in pairs and had their own differentiated responsibility areas (e.g. interior designers had interior design and lighting responsibilities) in the construction of a scale-model house. Because students in PBL need support in their learning, reflective discussions were organized after each lesson to ensure students' participation. Reflective discussions were video recorded, transcribed, and analyzed using a content and cooccurrence network analysis. The analysis revealed that teacher-directed reflective discussions first focused on supporting the cooperation of all students and then ensured the continuity of the process with most of the pairs. Some pairs, consisting of students with learning difficulties, needed intensified support until they could actively participate. The results indicate that teacher-directed reflective discussions improve students' cooperation skills and promote participation. A carefully prepared group composition enables the teacher to give intensified support to those students who need it most. In light of the results, we recommend that teachers focus on group composition when preparing inclusive, maker-centered PBL projects and use reflective discussions during said projects to promote inclusion and support students' active participation.
\end{abstract}

Keywords Cooperation · Inclusion · Maker-centered learning · Participation · Projectbased learning

\section{Introduction}

In the past decade, there has been considerable research regarding the approaches of students in terms of learning together and constructing competences through

Electronic supplementary material The online version of this article (https://doi.org/10.1007/s10763-01909998-9) contains supplementary material, which is available to authorized users. 
engagement. For example, in project-based learning (PBL), students engage in scientific and engineering practices when constructing an artifact together (Blumenfeld, Soloway, Marx, Krajcik, Guzdial, \& Palincsar, 1991; Krajick \& Merritt, 2012), and in maker activities, students learn while they make, tinker with, or engineer something shareable (Martinez \& Stager, 2013). This type of learning is considered useful to prepare students for the twenty-first century (Binkley, Erstad, Herman, Raizen, Ripley, Miller-Ricci, \& Rumble, 2012). When building competences together, students practice and learn how to interact with others, work in diverse teams, and participate in different roles as participants, mentors, or leaders (Binkley et al., 2012). In countries that follow the principles of inclusion, there is a need for maker approaches and practices that support the learning of a wide variety of students. In inclusive education, students with different backgrounds, preferences, interests, learning abilities, and identified special educational needs such as learning difficulties (LD) learn together with mainstream students as members of a group (Halinen \& Järvinen, 2008; Hick, Kershner, \& Farrell, 2009). Similar to inclusive education, in cooperative learning, students work and interact to maximize every student's learning by supporting each other. They also gain cooperative skills in addition to academic knowledge (Johnson \& Johnson, 2013).

Previous research findings concerning LD students indicate that in inclusive science classes, hands-on learning and investigations are beneficial for learning scientific and engineering practices (Bell, 2002; Lee \& So, 2015). Further, Alper (2013) as well as Martinez and Stager (2013) proposes that it is possible to engage all students in learning when construction and maker activities are connected to PBL. In addition, Tomlinson (1999) emphasizes systematic differentiation as a means of engaging students. Despite these encouraging research results, many teachers face problems in implementing inclusion in their science classrooms (Pesonen, Itkonen, Jahnukainen, Kontu, Kokko, Ojala, \& Pirttimaa, 2014). One major challenge teachers face is organizing cooperative learning, where students with LD can participate as true members of a group (Jenkins, Antil, Wayne, \& Vadasy, 2003). Even though cooperative learning relies on positive interdependence, the mutual support of group members is often not sufficient in inclusive classes: The additional support of a teacher is needed for less capable group members (Jenkins et al., 2003). Cooperation skills, especially group and social skills, seem to be crucial in cooperative activities, as working in such diverse groups is challenging for both mainstream and LD students. The teacher's role in fostering participation and social interaction within groups is essential and leads to the encouragement of students with disabilities and low social status to actively participate (Cohen, 1994). This is especially important when one acknowledges the worrisome observations that LD students are generally less accepted by their peers (Pijl \& Frostad, 2010). It has a negative effect on LD students' perception of self and personal belief, and this might negatively affect LD students' participation in cooperative practices and eventually hinder inclusion (Pijl \& Frostad, 2010). In order to enhance equity and equal learning opportunities, it is necessary to take students' individual needs into consideration when organizing cooperative maker activities (Binkley et al., 2012; United Nations Educational, Scientific, and Cultural Organization [UNESCO], 1994).

In sum, there are no explicit studies of maker approaches in inclusive classes. However, based on the findings of different research fields, maker approaches have the potential to support the learning of all students in terms of scientific- and engineering-related skills, inquiring and problem-solving skills, and group skills (e.g. 
Bell, 2002; Brigham, Scruggs, \& Mastropieri, 2011; Johnson \& Johnson, 2013; Krajcik $\&$ Shin, 2015). However, it is often difficult for practitioners to implement the scattered research findings in relation to the beneficial strategies, structures, and operating procedures that support LD students' knowledge and skill-building, enhance all students' active participation and acceptance, and promote inclusion. More research is needed in order to implement these inclusive practices in science classrooms. For this reason, we carefully create a framework in this study in which to put the previous research findings into practice. In the theory section, we will describe in detail inclusive, maker-centered PBL, an inclusion-supportive approach with practices that support students' learning. The empirical case study focuses on a teacher's actions when student participation and group skills are enhanced via reflective discussions following each session of inclusive and maker-centered PBL project.

\section{Inclusive Practices in Maker-Centered PBL}

Based on our literature review, we suggest that in inclusive classes, maker-centered PBL projects are convenient because they are adaptable to different kinds of learners and provide a structure in which the teacher can differentiate the learning process and/ or the act of creation (Alper, 2013; Bell, 2002; Brigham et al., 2011; Lee \& So, 2015; Martinez \& Stager, 2013). PBL is a pedagogical approach designed according to the research outcomes of learning science, and it emphasizes the following characteristics (Krajcik \& Shin, 2015): Students are active in learning by participating cooperatively in scientific and engineering practices (e.g. investigating questions, proposing explanations, arguing for their ideas), and students create a set of tangible products and shared artifacts that are publicly accessible to external representations. In Martinez and Stager's (2013) "learning by making" concept, making refers to working with tools and materials; tinkering refers to a playful, problem-solving mindset; and experimentation, discovery, and engineering refer to the application of scientific principles to design, build, and invent. Krajick and Merritt (2012) have emphasized the use of various scientific and engineering practices, such as questioning, observing, measuring, designing, and analyzing, as part of PBL. In doing so, students engage in processes that are central to the discipline.

In inclusive classes, knowledge practices surrounding making, tinkering, and engineering can nourish PBL by underlining the act of creation in a natural context. However, the needed tools, processes, and practices are often unpredictable, and it is common for several experiments, failures, and reproductions to be carried out before the final product is created. Without structure or content, these nonlinear and emergent processes may be demanding for LD students (Bell, 2002; Brigham et al., 2011). According to Lee and So (2015), differentiated and personalized activities could alleviate difficulties for LD students. In their research, simple tasks helped students connect said tasks to their everyday lives and thus form scientific concepts. They suggest that students with different abilities should focus on tasks at different levels; high achievers could study tasks in more depth using methods that are different to those of LD students (Lee \& So, 2015). According to Tomlinson (1999), a teacher can systematically differentiate content, process, and product in class. Content is what the teacher wants students to learn and the materials or mechanisms through which this is 
accomplished. Process describes activities designed to ensure that students use their key skills to make sense of essential ideas and information. Products are vehicles through which students demonstrate and extend what they have learned (Tomlinson, 1999). Considering these notions, we use the term "inclusive, maker-centered PBL," in which students with or without LD learn together over an extended period of time in terms of differentiation, focusing especially on process, and the teacher's way of supporting students' active participation in the task.

\section{Support for Maker Practices}

A successful, inclusive, maker-centered PBL process demands the active participation of all students. This can be accomplished by paying attention to the development of the skills needed for cooperation. According to Cohen (1994), in cooperative activities, the teacher should focus on factors affecting students' active participation (e.g. the clarity of the task and the degree of social interaction between students). At the beginning of the project, the teacher's careful preparation and structuration are particularly necessary. Clear instructions regarding the tasks and visible learning goals support students and lead to productive interaction in the group (Cohen, 1994; Martinez \& Stager, 2013). In addition, there is a need to differentiate teaching and learning between students who will benefit from additional challenges and students with LD who need customized strategies to achieve learning goals. In inclusive classes, the teacher's pedagogic support should be responsive to learners' varying readiness, interests, and skills; should attend to group composition when preparing the project; and should attend to process support during the project (Brigham et al., 2011; Jenkins et al., 2003; Tomlinson et al., 2003).

Group Composition. The abilities of students have a dominant effect on social interactions in the group. Based on a research review, a carefully designed group composition relies on heterogenous groups and interconnected group roles that create the foundation for an inclusive group (e.g. Jenkins et al., 2003; Webb, Nemer, Chizhik, \& Sugrue, 1998). Heterogeneous groups are found to be especially beneficial in inclusive classes (e.g. Webb et al., 1998). Jenkins et al. (2003) identified the grouping and selection of suitable partners for LD students as a primary modification in collaborative activities. However, the students' competences must not be too dissimilar. For example, Esmonde (2009) argues that having high-achieving students in a group may hinder the learning opportunities of less confident students. When selecting suitable partners, the students' social status should also be considered. Cohen (1994) notes that the students' status defines how decisions are made in a group. Having a student with low social status might result in low participation and impede member interaction. In inclusive classes, these notions should be considered in project preparation, especially when one considers the results stemming from LD students' acceptance within their respective peer groups (cf. Pijl \& Frostad, 2010). Anderson, Thomas, and Nashon (2008) theorize that students are aware of their social status, and in the case of students with low social status, it negatively affects their self-esteem, cognition, and behavior. According to Webb et al. (1998), group composition has a major impact on the quality of group discussions. In their study, below-average students performed better if they worked with above-average students, while above-average students performed as well when working alone or in different group combinations. 
In preparation for the project, the teacher should ensure that every student finds a meaningful role in the group, regardless of the student's social status or self-concept. Previous studies indicate that LD students' active participation can be facilitated by assigning complementary and interconnected roles, according to each student's strengths (Johnson \& Johnson, 2013). In Stamovlasis, Dimos, and Tsaparlis's (2006) group-interaction study, highly active groups benefitted from a proactive leader and member(s) who facilitated group discourse. However, assigning specific roles might cause students to focus solely on their own tasks without interacting with others (Cohen, 1994). Allowing students to position themselves and others in a group at the beginning is beneficial for future negotiations and for alleviating possible group tensions (Sullivan \& Wilson, 2015). Cooperation is often productive in groups when students with diverse abilities work together, and this may provide encouraging examples to LD students (Tomlinson et al., 2003).

Process Support. Consequently, group composition plays a major role of differentiation in cooperative processes, as maker-centered PBL projects with nonlinear and emergent processes could cause uncertainty. In particular, students with social difficulties need intensified support in order to actualize the potential benefits of a heterogeneous grouping. Empirical studies on maker-centered PBL illustrate the teacher's role as a facilitator, mentor, and supervisor of the student learning process. The teacher's role is to facilitate learning by encouraging independent work as much as possible throughout the process (Gómez Puente, van Eijck, \& Jochems, 2013). However, the need for more intense support is occasionally required. Jenkins et al. (2003) investigated teachers' perceptions of cooperative learning in inclusive classes. Several teachers reported that LD students needed more direct and intensified adult involvement in their group work, which varied in different classes consisting of students with different needs. In 1 class, the teacher joined a group that had a "difficult-to-manage student" in order to help them become accepted by other group members. In another class, 3 teachers reported taking a struggling student aside to support them in completing the group task. The effectiveness of the supporting strategies described above is admittedly dependent on learning goals. In cooperative maker projects that focus on the development of cooperation skills, the teacher should give students the necessary space to work independently without too much disruption (Cohen, 1994). However, a teacher-given model and regular feedback throughout the process is beneficial to all students. A teacher's intensified support could be given after the active cooperative period at the end of the lesson. It is noteworthy that it takes time for LD students to become familiar with new approaches; this is why it is important to use the same methods regularly and with similar structures (Cook \& Schirmer, 2003). Teachers also benefit from iterative practices and routines that help to give regular feedback to students. For example, van de Pol, Volman, Oort, and Beishuizen (2014) learned that teachers benefitted from a structural model of promoting students learning. Teachers who used this model provided more support to students.

Based on previous studies, we include systematic teacher-directed reflections in relation to our maker-centered PBL project. We characterize reflective discussion as a means of enhancing students' cooperation skills and inclusion in a maker-centered PBL science class by giving students both the space to develop their skills independently and reflect on them with the teacher's support. In teacher-directed reflective discussions, the 
teacher supports the students' active participation, ensures progress in the project, and facilitates learning. We expect that teacher-directed reflective discussions will provide a model of interaction for student learning in maker-centered PBL. We will thus contribute to this area of research. The following research question is explored in this paper: With what issues does a teacher's support focus on reflective discussions, and how does this support promote active participation?

\section{Method}

\section{Context of the Study}

Finnish compulsory education is based on the philosophy of inclusion and the personalization of learning. Basic education is free of charge and it is same for all students. In addition, students are supported individually based on their needs to ensure that they can complete their studies successfully (Finnish National Agency of Education, 2016). In Finnish education practices, LD are often described as problems in language (i.e. reading, writing, speaking, and listening), mathematics, attention, action control, perception, and fine or gross motor skills. It is generally understood that these difficulties might negatively affect their self-esteem and overall sense of well-being (Niilo Mäki Instituutti, 2015). In Finland, the implementation of inclusive practices varies in different municipalities, but the national curricula guarantee successful learning for all in inclusive classrooms through strategies, structures, and operating procedures in every school (Halinen \& Järvinen, 2008).

The maker-centered PBL project was conducted in a primary school in the capital area of Helsinki, Finland. On average, 1 out of every 6 students had identified LD and had a guarantee of enhanced support at school. This support was determined in collaboration with a multi-professional team, selected according to Finnish education practices (The Finnish Basic Education Act, 642/, 2010). Teachers worked in teams of $1-2$ class teachers and 1 special education teacher to implement inclusive education with the support of school management. The participating class had 2 primary teachers (1 teacher had a Master of Education [M.Ed.] and specialized in technology education, the other teacher had a Bachelor of Education), 1 classroom assistant (vocational qualification), and 1 special education teacher (M.Ed., specialized in special education). The special education teacher is the corresponding author of this paper. The teachers had worked together for 3 years in the same class, and they all had previous experience (ranging from 6 to 8 years) in team teaching. In the classroom, the teachers' support was available to all students. Both the maker activities and PBL practices were gradually introduced and practiced with all students before the research period. Digital technology (i.e. computers, laptops, tablet devices, and mobile phones) and fabrication tools (e.g. metal, textiles, wood) were also used systematically in the class from the first grade, according to the guidelines of the Finnish National Curriculum (The Finnish National Agency of Education, 2016).

Maker-Centered Project. The project was organized in accordance with the principles of PBL (Krajic \& Shin, 2015), various scientific and engineering practices 
(Krajick \& Merritt, 2012), and differentiation (Tomlinson, 1999). It also included elements of "learning by making" (Martinez \& Stager, 2013). The actual makercentered PBL process was grounded in 4 major ideas: active construction, situated learning, social interaction, and cognitive tools (Krajcik \& Shin, 2015). In this inclusive maker-centered PBL process, students focused on scientific and engineering learning by making, tinkering with, and engineering an artifact together. In this project, the artifact was a scale-model house. Table 1 presents the structure of the maker-centered PBL project. The maker-centered PBL project was designed by the team of teachers so as to integrate science, engineering, arts, crafts, and mathematics by focusing on both process and product, according to the Finnish National Curriculum (The Finnish National Agency of Education, 2016). The students built on their previous knowledge and skills at different challenge levels (active construction). They worked with authentic, real-world problems (situated learning) and cooperated at different levels (as a pair or with the whole team) (social interaction) using cooperative learning practices (Johnson \& Johnson, 2013). The technology was used in fabrication activities as well as in digital note-making practices that digitally documented their process (cognitive tools). During the sessions, the teacher monitored the students' work and was available for them if needed. The project began with the introduction of the topic, followed by questions, data gathering, and evidence gathering. In the first 3 phases (consisting of 1 session each), all the students studied the mandatory content of the curriculum in relation to electricity (i.e. renewable and nonrenewable energy, frictional electricity, power supplies, basic electrical circuits, electrical safety, and the use of electricity to produce heat, light, and movement).

After the first 3 phases, the process continued with differentiated phases that were based on the students' learning interests and needs (Tomlinson, 1999). The phases consisted of a planning and goal-oriented activity (consisting of 2 sessions), researching and/or creating an outcome or formulating an answer to the original question (consisting of $1-3$ sessions), and modifying their responsibility areas (consisting of 2 sessions). Finally, the teams presented their final artifact, a scale-model house, to their parents and the other teams (consisting of 1 session). In total, the project involved 8 phases and 11 90-minute sessions.

Reflective Discussions. After each session, the teacher and students reflected upon the finished session in teacher-directed reflective discussions. The aim here was to give students the space to independently develop their group skills during the session (Gómez Puente et al., 2013) and obtain support after it. The reflective discussions followed a specific structure, consisting of general and follow-up questions, so that the students could become familiar with the approach (Cook \& Schirmer, 2003). The questions were based on various PBL principles (Krajcik \& Shin, 2015) with respect to active construction (e.g. How challenging was the task? Did you have the enough skills to do it? How interesting was the task?), social interaction (e.g. How much did you cooperate with your pair or other team members? Were you all equally interested in the task?), and cognitive tools (e.g. Did you use digital technology? What did you do?). When problems were raised in the discussions, the teacher guided the students or set examples as to how to begin, share tasks, and support other members when working in a group. 
Table 1 The structure of the maker-centered PBL project

\begin{tabular}{ll}
\hline $\begin{array}{l}\text { Phase } \\
\text { (amount of sessions) }\end{array}$ & $\begin{array}{l}\text { Description of teacher's preparation } \\
\text { and support }\end{array}$ \\
\hline $\begin{array}{l}\text { Orienting } \\
\text { (1 session) }\end{array}$ & $\begin{array}{c}\text { The project as well as the use of digital } \\
\text { technology, especially smartphones, } \\
\text { was introduced to the students. The } \\
\text { phones would be used in orientation, } \\
\text { reporting, and reflection. }\end{array}$
\end{tabular}

Asking questions (1 session)

The teacher grouped students together based on the pre-questionnaire and the
Information gathering (1 session)

Planning (2 sessions)

Researching and creating (1 differentiated session)
Creating (2 sessions) The teacher checked the students' work and gave written feedback.

Modifying

(2 sessions)

Presenting

(1 session) and gave written feedback.

The teacher encouraged the students. students' abilities. The teacher prepared a cooperative e-learning space in OneNote with work instructions for the next session.

\section{The teacher devised} information-acquisition questions for the pairs, based on their sub-projects and previous knowledge and observations.

The teacher read the students' work and gave feedback.

The teacher set up work instructions for the session in the e-learning space.

The teacher checked the students' work and gave feedback. The teacher set up work instructions for the session in the e-learning space.
Description of maker practices

The students filled out the pre-questionnaire. They made observations and took photos of electricity in the school and its surroundings.

The team categorized their observations and wrote down their existing knowledge, based on the project's main question: "How does energy reach the different devices in the house, and where does this happen?"

The students amassed some clarifying questions for the project's driving question.

The pairs searched for information regarding the questions from a variety of information sources and information and communications technology tools, such as electricity videos made in the fourth grade. They wrote a report in the e-learning space.

The pairs read the feedback and finished their reports based on this feedback. They then presented their report to the team. The team made plans together.

The pairs planned their responsibility areas and made sketches on paper. Their finished plans were uploaded to the e-learning space. The whole team compared and combined each pair's plans to match other plans.

The pairs worked on their own responsibility areas. After every session, they reported on their progress with photos and a short descriptive text.

Researching: The electricity producers and electricians formulated various inquiry activities to deepen their understanding of the science topic.

Creating: The builders, interior designers, and landscapers constructed their own responsibility areas.

All the pairs continued working on their own responsibility areas.

The team finished their products.
The team presented their scale-model houses to an audience (i.e. their parents and the other teams). 
Group Composition and Differentiation. In the project, the 44 students were grouped into 4 teams of mixed abilities (with 10-12 members in each team), with each team constructing its own scale-model house. In each team, the students worked in pairs on personalized sub-projects. Table 2 presents the sub-projects of each pair in the scalemodel house; these sub-projects were differentiated according to content, process, and product (Lee \& So, 2015; Tomlinson, 1999). For every pair, the curriculum content of electricity was embedded in their sub-project. For example, the sub-project of the electricity producers, with more challenging content and products, was designed for high-achieving students who were motivated to learn more than what was required and were inspired by challenging tasks. The electricity producers' final product also comprised a report on which forms of renewable energy should be chosen for the house.

The teacher decided on the composition of pairs for each team according to a prequestionnaire on the principles of differentiation (Tomlinson, 1999), thus ensuring a balance of students' abilities and assistance for each student in the group (Esmonde, 2009; Jenkins et al., 2003; Johnson \& Johnson, 2013; Webb et al., 1998). In the prequestionnaire, the students were asked the following questions: (1) Name 3 pupils with whom you can work successfully in the group. (2) Name 3 pupils with whom you CANNOT work successfully in the group. (3) Pick a task in which you think you are going to succeed and that you find interesting: (a) woodwork and building a house; (b) electrical tinkering; (c) sewing and tinkering; (d) tinkering and outdoor designing; (e) innovating, testing, and problem-solving. The pre-questionnaire was used only for group composition, not for data analysis. Each of the 4 teams had 1 adult (a teacher or classroom assistant) as a team mentor to whom students could turn to if they needed support. The main focus of the support was to ensure the students succeeded in cooperating and in the maker process. The same teacher followed the team's progress, both in action and digitally, on OneDrive, the Microsoft cloud service. The students'

Table 2 Differentiation in the scale-model house project

\begin{tabular}{|c|c|c|c|}
\hline \multirow[t]{2}{*}{ Sub-project } & \multicolumn{3}{|l|}{ Differentiation } \\
\hline & Content & Process & Product \\
\hline $\begin{array}{l}\text { Electricity } \\
\text { producers }\end{array}$ & $\begin{array}{l}\text { More challenging curricula content } \\
\text { (i.e. renewable energy). }\end{array}$ & $\begin{array}{l}\text { Independent } \\
\text { work. }\end{array}$ & $\begin{array}{l}\text { More challenging product: Report on the } \\
\text { chosen renewable energy form. }\end{array}$ \\
\hline Electricians & $\begin{array}{l}\text { More challenging curricula content } \\
\text { (i.e. electrification). }\end{array}$ & $\begin{array}{c}\text { Based on } \\
\text { current } \\
\text { needs. }\end{array}$ & Electrification. \\
\hline Builders & $\begin{array}{l}\text { Regular curricula content } \\
\text { (i.e. the basics of electrical } \\
\text { circuits and electrical safety). }\end{array}$ & $\begin{array}{c}\text { Based on } \\
\text { current } \\
\text { needs. }\end{array}$ & Building the house from wood. \\
\hline $\begin{array}{l}\text { Interior } \\
\text { designers }\end{array}$ & $\begin{array}{l}\text { Regular curricula content } \\
\text { (i.e. the basics of electrical } \\
\text { circuits and electrical safety). }\end{array}$ & $\begin{array}{c}\text { Based on } \\
\text { current } \\
\text { needs. }\end{array}$ & Interior design with lightning. \\
\hline Landscapers & $\begin{array}{l}\text { Regular curricula content } \\
\text { (i.e. the basics of electrical } \\
\text { circuits and electrical safety). }\end{array}$ & $\begin{array}{c}\text { Based on } \\
\text { current } \\
\text { needs. }\end{array}$ & Outdoor design and lightning. \\
\hline
\end{tabular}


digital notes enabled teachers to follow the students' progress and possible digital cooperation.

\section{Participants}

The current research examines how teacher-directed reflective discussions affect students' active participation. The research followed a case study methodology (Stake, 2005 ) in order to fully explore the inclusive, maker-centered PBL process; the reflective discussion; and the teacher's role in said discussion. To meet the research goals, among the 4 teams, 1 team (4 LD and 7 mainstream students, aged $12-13$ years) was selected as the focal team. The class's teachers chose the focal team based on the group with the most varied composition in terms of mainstream and LD students (Table 3). Relying on the case study methodology, the class's teachers decided to only hold reflective discussions with the focal team and applied the learned practices of this project to forthcoming projects.

The students were assigned into pairs in different combinations so that the teacher could later identify which pairs needed more intensified support in the reflective discussions. Maria and Emilia (pseudonymous names) were assigned the roles of electricity producers. They were often paired with LD students because of their good group skills. The class's teachers expected that in this project, both girls would benefit from the content and product differentiation. The electricity producers and electricians had a research phase in their process, and this allowed the teacher to give these students more challenging work. Both Tuomas (LD) and Mikael, the electricians, needed more challenges with the content, but Tuomas needed more support in social situations, and Mikael benefited from the more challenging process. With the builders, Lauri (LD) needed support for the process because he tended to retreat during cooperative activities. However, he had good craft skills, so teachers thought he would benefit from a more challenging maker product. Lauri's partner, Matias, did not have any additional need for differentiation, and neither did Sofia nor Julia, the interior designers. Only students with LD (Eetu, Jere, and Aleksi) were assigned the roles of landscapers, based on their common need for product differentiation. However, since Jere and Aleksi both needed process support, and because Eetu had good social skills, the class's teachers decided to give Eetu extra challenges in the process.

\section{Data Collection}

The data was collected from video recordings of reflective discussions and students' digital notes. The mentoring teacher worked in the class as usual, supporting students' cooperation, ensuring the process was going smoothly, and facilitating learning. The teacher's observations were only detectable in the reflective discussions. The focal team had reflective discussions following each session. The class's teachers agreed that the corresponding author should mentor the focal team during the process. She also led the focal team's discussions because she had worked in a class as a special education teacher for 6 years. Based on Stalker's (1998) study, it is essential that the researcher knows the participants well when studying students 
Table 3 Analyzed student pairs, their sub-projects, and students' background information

\begin{tabular}{|c|c|c|c|}
\hline \multirow[t]{2}{*}{ Sub-project } & \multirow{2}{*}{$\begin{array}{l}\text { Student } \\
\text { (pseudonym) }\end{array}$} & \multicolumn{2}{|c|}{ Background information } \\
\hline & & Gender & Predominant differentiation needs \\
\hline \multirow[t]{2}{*}{ Electricity producers } & Maria & Female & $\begin{array}{l}\text { Basic process (good social skills) } \\
\text { More challenges to content and product }\end{array}$ \\
\hline & Emilia & Female & $\begin{array}{l}\text { Basic process (good social skills) } \\
\text { More challenges to content and product }\end{array}$ \\
\hline \multirow[t]{2}{*}{ Electricians } & Tuomas (LD) & Male & $\begin{array}{l}\text { More challenges to content (good technology skills) } \\
\text { Support for process (social situations) } \\
\text { Basic product }\end{array}$ \\
\hline & Mikael & Male & $\begin{array}{l}\text { More challenges to content and process (good social skills) } \\
\text { Basic product }\end{array}$ \\
\hline \multirow[t]{2}{*}{ Builders } & Lauri (LD) & Male & $\begin{array}{l}\text { Basic content } \\
\text { Support for process (low self-esteem) } \\
\text { More challenges to product (LD in language, } \\
\quad \text { good maker skills) }\end{array}$ \\
\hline & Matias & Male & Basic content, process and product \\
\hline \multirow[t]{2}{*}{ Interior designers } & Sofia & Female & Basic content, process and product \\
\hline & Julia & Female & Basic content, process and product \\
\hline \multirow[t]{3}{*}{ Landscapers } & Eetu (LD) & Male & $\begin{array}{l}\text { Basic content and process (good social skills) } \\
\text { Support for product (LD in language) }\end{array}$ \\
\hline & Jere (LD) & Male & $\begin{array}{l}\text { Basic content } \\
\text { Support for process (social situations) and product } \\
\text { (LD in language) }\end{array}$ \\
\hline & Aleksi (LD) & Male & $\begin{array}{l}\text { Basic content } \\
\text { Support for process (social situations) and product } \\
\text { (LD in language) }\end{array}$ \\
\hline
\end{tabular}

with LD. The reflective discussions were video recorded after each session (11 sessions in total; duration of $1-4$ minutes per session), producing roughly 1 hour 30 minutes of video material. During the project, the students digitally documented the process. They also wrote notes and took photos of their process at the end of each session and saved it to their team's file on OneDrive, Microsoft's cloud service. At the end of the project, the team's file consisted of 19 documents, a total of 35 PDF pages.

\section{Data Analysis}

The data analysis occurred in phases. The corresponding author conducted the preliminary analysis after each data analysis phase and presented the findings to the other authors. Their observations were discussed until a mutual understanding was reached. The data analysis was performed using the procedures of a qualitative content analysis (Stake, 2005), and the data were clarified during our discussions between data analysis phases. For the project, all of the reflective discussions and digital notes were organized in chronological order, and the interviews were transcribed. In the first data analysis phase, data from each session were organized 
into small data sets, where the students' active participation and required teacher support in different phases of the project could be detected. If the student was participating in an activity as part of a pair, we identified the degrees of social interaction and connection between both students in the pair. If the students displayed cooperation or social interaction with other pairs or students outside of their own pair, the social interaction of those students was identified. Teacher support was similarly identified from the data.

The data was summarized into a graphical form using the co-occurrence network analysis with Gephi, which is a form of open-source software for data visualization (Bastian, Heymann, \& Jacomy, 2009), and it was visualized with Force Atlas 2, a spatial layout algorithm (Jacomy, Heymann, Venturini, \& Bastian, 2012). The processes of the focal team and the sub-processes of the 5 pairs were created, thus enabling us to identify patterns and interpret the data. Figure 1 visualizes the participation of the focal team and support of the teacher in the PBL process. The project phases are in white dots with titles above them. In the middle of the figure, it is noted that the electricity producers and electricians had a differentiated process phase, where they conducted research and studied the electricity content in a more in-depth manner. Students are depicted by the gray dots and are grouped near their pairs. Lines between the students visualize the social interaction between participating students, identified if a student/pair mentioned cooperation with other students/pairs. The number of lines between the students indicates the frequency of social interaction during the process; a small number of lines indicates low levels of participation, while many lines indicate active participation. A teacher's support is depicted in red and is linked to students or pairs. From the visualization, we identified the phases and sessions where students cooperated the most and identified students who were most active or those who withdrew from cooperative situations. We also identified pairs who most needed the teacher's support. (The complete co-occurrence graphs can be seen in the supplementary online materials.) We then analyzed the teacher support sections in more detail through a data-driven content analysis. During the analysis, 2 themes emerged in terms of when the teachers gave support: "support with the process" and "support with social interaction" (Table 4). Finally, we compared the findings with the transcribed reflective discussions and digital notes, focusing on the students' social interactions and teacher support. Throughout the analysis, the text transcriptions were read several times, and the gathered data were compared.

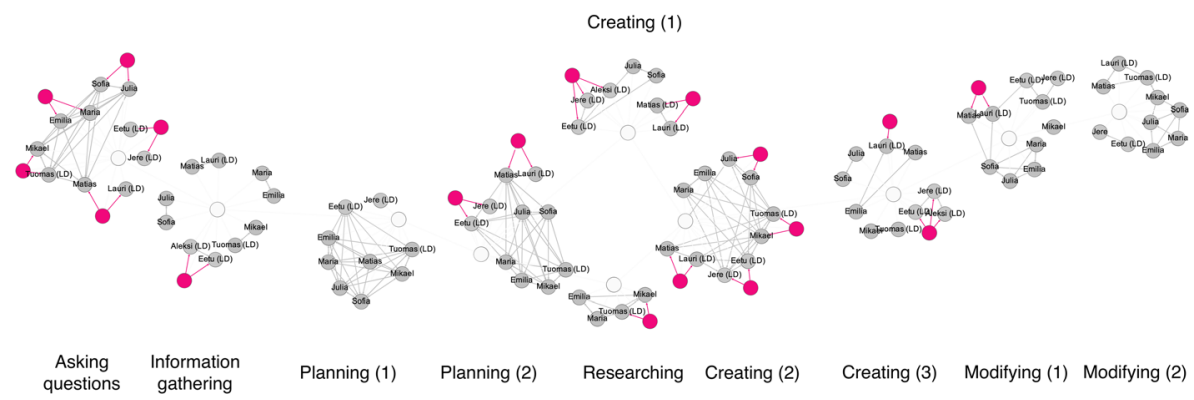

Fig. 1 The focal team's participation and teacher support in the scale-model house project 


\section{Findings}

The aim of this study was to explore how teacher-directed reflective discussions support student participation in different phases of an inclusive and maker-centered PBL project. We first describe the team's process and participation in a site of social interaction from the perspective of the maker-centered PBL phases (Table 1 and Fig. 1). After this, we discuss the characteristics of the teacher's differentiated support in the different phases. The citations are from the reflective discussions.

\section{Social Interaction During the Maker-Centered PBL Process}

During the first 3 sessions, the students studied electricity in a cooperative manner. In the "asking questions" session, the students made observations together as a team, while in the "information gathering" session, the sub-project pairs concentrated on a specific topic. In the first "planning" session, the pairs shared their gained knowledge with the team. In both "asking questions" session and first "planning" session, the students worked with the whole team, and social interaction between students was more frequent. In those sessions, some LD students were separated from other students in the team. For example, in the "asking questions" session, there were no interaction lines between Lauri (LD, builders), Jere (LD, landscapers), or Aleksi (LD, landscapers) and the other team members, and in the first "planning session," Jere (LD, landscapers) withdrew from the others (no interaction lines). In the "information gathering" session, the students worked within their own responsibility areas and only socially interacted with the other member of their pair. In the second "planning"

Table 4 Structure of the coding template and analysis of unit descriptions

\begin{tabular}{|c|c|c|}
\hline Theme & Category & Example of analysis unit \\
\hline \multirow[t]{4}{*}{$\begin{array}{l}\text { Support with the } \\
\text { process }\end{array}$} & What to do next & $\begin{array}{l}\text { "I think you [electricians] should cooperate with the interior } \\
\text { designers next time. They needed your help." }\end{array}$ \\
\hline & $\begin{array}{l}\text { Extra support at the } \\
\text { beginning of the } \\
\text { session }\end{array}$ & "I came to see you [builders] at the beginning of the session." \\
\hline & Content support & $\begin{array}{l}\text { "You [electricians] should plan how to do wiring to the house } \\
\text { so that the interior designers can continue their work." }\end{array}$ \\
\hline & Positive feedback & "Well done." \\
\hline \multirow[t]{5}{*}{$\begin{array}{l}\text { Support with } \\
\text { social } \\
\text { interaction }\end{array}$} & $\begin{array}{l}\text { How to be a group } \\
\text { member }\end{array}$ & $\begin{array}{l}\text { "Is it enough that Eetu tells you [Jere, LD] what to do, or do } \\
\text { you want me to guide you next time?" (first "creating" } \\
\text { session) }\end{array}$ \\
\hline & How to lead & "You [Matias] could ask how we're going to share today." \\
\hline & How to cooperate & $\begin{array}{l}\text { "You [Lauri, LD] could be interested and ask what we are } \\
\text { going to do today." }\end{array}$ \\
\hline & Direct confrontation & $\begin{array}{l}\text { "Can you [Aleksi, LD] take guidance from Eetu, or do you } \\
\text { need my help, or do you want me to give you some other } \\
\text { work during this project?" }\end{array}$ \\
\hline & Negotiating & $\begin{array}{l}\text { "You [landscapers] can do electricians' tasks also, like wiring, } \\
\text { if you make outdoor lighting." }\end{array}$ \\
\hline
\end{tabular}


session, students made plans for their own sub-projects, but they were obliged to share their plans with the rest of the team at the end of the session. Figure 1 shows that in this session, Lauri (LD, builders) and Jere (LD, landscapers) withdrew from the others, with no interaction with their team members. In the first "creating" session and "researching" session, the pairs of students again worked within their own responsibility areas, and only Aleksi (LD, landscapers) did not have any interaction with the other landscapers.

In the second "creating" session, the students were instructed to work within their own responsibility areas, but in this session, they needed to cooperate with the other sub-project pairs. In Fig. 1, the amount of interaction lines indicates that all of the students were actively participating in this session. In the third "creating" session, the first "modifying" session, and the second "modifying" session, the students' social interactions varied. For example, in both "modifying" sessions, the electricity producers and electricians began to help other students when they finished their own subprojects. In the first "modifying" session, Mikael (electricians) seemed to be separated from the others, but he focused on building a switch for the lighting of the house alone, in agreement with Tuomas (LD). Based on the overview of students' social interactions in the scale-model house project in Fig. 1, we assume that the diminishing need for teacher support indicates the learning of competences required for the process. However, 4 of the 5 LD students had difficulties participating at the beginning of the project. As expected, the landscapers (LD students) needed more intensified teacher support (see Table 3). This was not the case with the builders' (Lauri, LD; and Matias), who needed teacher support throughout the project. This had been assumed at the projectplanning stage.

\section{Reminding Students How to Cooperate at the Beginning}

Teacher support varied during the project (Fig. 1; in red). At the beginning of the PBL process, the need for teacher support was evident in all pairs. In the "asking questions" session (Fig. 2), the teacher's support of cooperation appeared in all of the reflective discussions conducted by the pairs. During these discussions, they considered the value of each member's participation, how to succeed in the task, and how to support the participation and role of each team member. For the electricity producers (Maria and Emilia), who needed more challenges with respect to content and product, the teacher's role was only important at the beginning of the project.

The electricity producers' co-occurrence graph can be seen in Figure S-1 (see supplementary online materials). In the "asking questions" session, Emilia (electricity producer) took a leading role, which was protested by Maria (electricity producer) and Sofia (interior designer). In the reflective discussion, the situation had escalated, and the students seemed to be in a bad mood. The teacher took control, and the team discussed this issue:

Teacher:Why did you have difficulties in today's session?

Emilia:Because everyone talked over one [another], and you had to shout if you wanted to get your voice heard.

Teacher:Why did you talk over one another?

Sofia:There wasn't a leader in our team who gave turns. 


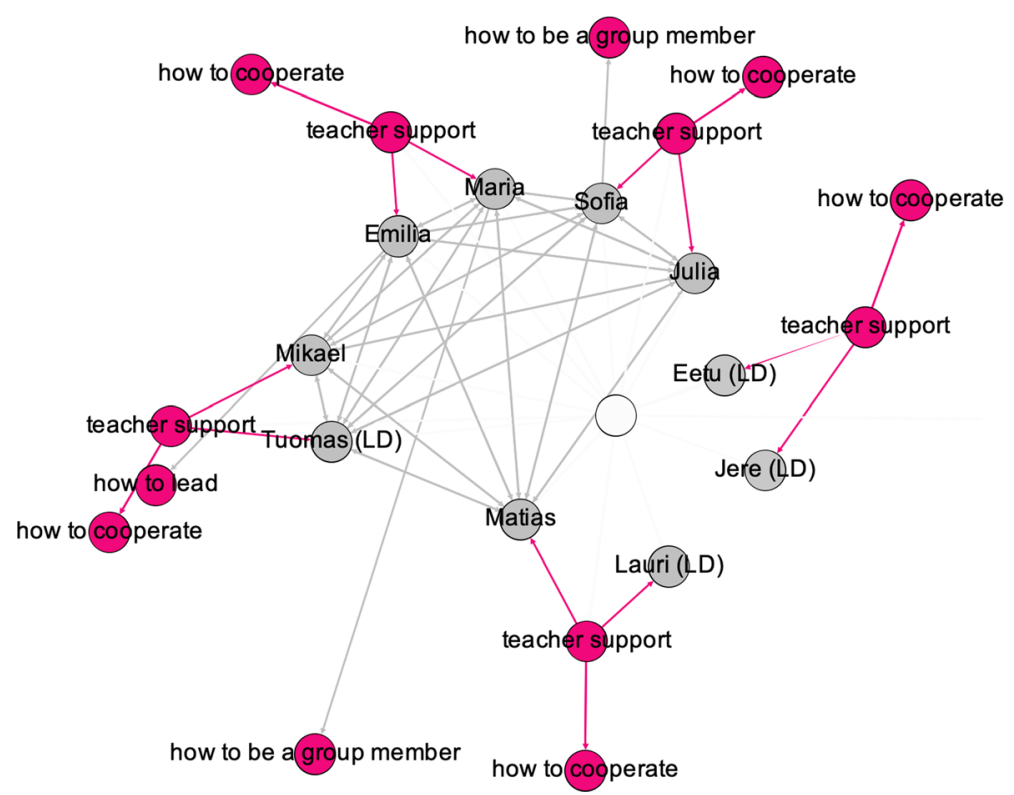

Fig. 2 The focal team's asking questions phase

Teacher:What did you want from the leader?

Sofia:Giving those turns.

Teacher:But Emilia did it sometimes, but ...

Emilia:But then Maria began to complain that you cannot govern here.

Maria:It would have been nice to give a turn to others also.

[The students start to talk over each other, and the teacher interrupts them.]

Teacher:[...] What happened today was that Emilia was domineering, and Maria and Sofia did not respect you [Emilia] as a leader, and they talked over you. The other team members could not be more active, because of your [...] disagreement. What do you think? This is how I felt when I followed your work today.

[The other students nod their heads.]

Teacher:[Addressing Maria, Emilia, and Sofia.] Every one of you can be good team members, and every one of you know[s] how to lead [...] What do you think $[\ldots]$ ?

Maria:[Smiles and nods.] Yes, I guess so.

[Emilia and Sofia are both smiling and nodding.]

After this first session, where the teacher robustly directed the reflective discussion, the electricity producers took account of their team's success in the different subprojects and began to support the whole team's process. Socially capable and skillful, Maria and Emilia regularly cooperated with the other pairs during the process, and when they were finished with their own responsibility area, they helped the landscapers, builders, and interior designers in their sub-projects. During the discussion, both students brought up their interest in maker activities. That interest might also have influenced their support of other pairs. 
Emilia:Can we paint the house?

Teacher:You have to ask [the builders]. So, you would like to make something for the house?

Emilia:Yes, or something like that. Something that relates to it.

Teacher:You can ask if you can do it.

However, the teacher encouraged the electricity producers to continue their own task in terms of their needs.

Teacher:Or would you like to [...] I was thinking whether you should think about an electricity transformer $[\ldots]$

Maria:Yes!

Teacher:[...]so you could make an electricity transformer or something like that for the house.

Emilia:Oh, yes.

\section{Ensuring the Progress of the Sub-project in the Planning and Creating Phases}

In the scale-model house project, science, engineering, arts, crafts, and mathematics were integrated. The teacher prepared lessons and included instructions for every session in the e-learning space so that students could easily follow their instructions and focus on their sub-project. Based on the backgrounds of the students (Table 3), the presumption was that carefully designed instructions would be a sufficient form of support for the electricity producers, interior designers, and electricians. We presumed that with the electricians, the mainstream student (Mikael) with good social skills who needed more challenging interactions would support Tuomas (LD), whose social skills were not as developed. However, teacher support varied more than expected during the project (Fig. 1; in red). For the most part, our presumptions were verified, but both the interior designers' and electricians' reflective discussions included process-related teacher support, especially in all three "creating" sessions (see Figures S-2 and S-3 in the online materials). In the second "creating" session, the electricians (Mikael and Tuomas, LD) had social interactions with all of the team members when they wondered what to do next. The electricians also needed encouragement (i.e. positive feedback) and more direct guidance on how to proceed.

Teacher:How was your session today?

Mikael:Well, quite easy.

Tuomas (LD):I agree.

Teacher:Is [sic] there going to be switches or something like that in the house?

Have you planned how to light the lamps, for example?

Mikael:Mmm, probably something like that, or something with basic connections, like the circuits. 
Teacher:Ok. I think I'm going to set you a task next time that you can exploit in the final building or when you are pulling the electricity.

The previous example shows that there were difficulties with timing in this project in relation to the specific responsibility areas; this created a need for teacher assistance, especially when the students were engaged in making activities in the "creating" phase. For example, the different pairs finished their products at different times or were dependent on the progress of others. In this case, the electricians (Mikael and Tuomas, LD) had to wait for the builders (Lauri, LD; and Matias) to finish the house and for the interior designers (Julia and Sofia) to make the lighting prototypes. However, the teacher guided the builders by setting an extra structured task for them and ensured that the interior designers had taken the electricians' work into consideration:

Teacher:Now, it is really important to make lighting prototypes next time so the electricians can continue their work.

Sofia:We made those lamps.

Teacher:So, you have done it. So, they [electricians] have a task for [the] next session?

Sofia:Yes, they [made lamps] are drying out.

Teacher:Good, really good! And then if you have some task, for example, for the electricity producers?

Sofia:I might know what they could do.

Teacher:Great that you have [an] idea for it.

The interior designers' (Julia and Sofia) product involved a lot of tinkering with furniture, lighting, decorations, and textiles. This took a lot of time. It was an easy task in which to receive help and give small assignments to others. The landscapers (Aleksi, LD; Eetu, LD; and Jere, LD) had a product similar to that of the interior designers, for which they also received help from others (see Figure S-4 in the online materials). However, it took time for them to engage in the sub-project because, according to the pre-questionnaire, they all wanted to work in other areas (see Table 2). As expected, the landscapers needed intensified teacher support (see Table 3). For example, in the second "planning" session, both Jere (LD) and Eetu (LD) were reticent during the first 3 minutes of the discussion. The teacher asked questions, and the boys replied in brief until the teacher guessed what was wrong and started to negotiate with them:

Teacher:Were you [Jere, LD] as interested in the task as [the] others?

Jere:No.

Teacher:Can you tell me why?

Jere:Well, it wasn't so interesting for me to make the yard.

Teacher:What about you, Eetu [LD]?

Eetu:Well, I don't know. Not so much.

Teacher:So, you are not so interested in making the yard, correct?

Eetu:No ...

Teacher:So how could we ... What would you like to do?

Eetu:Well, I would've liked to be an electrician or builder. 
Teacher:Ok. And you, Jere?

Jere:Same. Electrician or builder.

Teacher:Well, could we come up with something in the yard where you can do that [build and do electricity] as well?

Eetu:There is a terrace [in the plan].

Teacher:Well, that could be fun to do. I think that we can modify this task so that it is fun for you too.

The support given to the landscapers differed from the others (Figure S-4 in the online materials). All 3 of them (Aleksi, LD; Eetu, LD; and Jere, LD) were present in 2 sessions, and only Eetu (LD) was present in all 11 sessions. This had a negative influence on their independent cooperation and reflective discussions. The landscapers' reflective discussions had a tone that was different to the others because of the changing composition of the group. In the discussions, the teacher outlined Eetu's (LD) role in the group. For example, Aleksi (LD) had difficulties, and in the first "creating" session's reflective discussion, the teacher had to ask him the following question: "Can you receive instructions from Eetu (LD), or do you want me to give you another task?" After the second "creating" session, they again discussed the value of each team member's participation and how to support each team member's participation and role. The teacher also gave them positive feedback when they succeeded: "I feel like you did a really good job today. That's what I saw. So, $[\ldots]$ you really did well today." The landscapers received extra support at the beginning of the session. The teacher ensured that the process continued as planned following the return of every member.

\section{Modelling Cooperation in the Project}

The electricity producers (Emilia and Maria), interior designers (Julia and Sofia), and electricians (Tuomas, LD; and Matias) proceeded almost autonomously in their subprojects. It could be said that their group composition succeeded. These pairs shared their responsibilities, and the work was either led by 1 member (Sofia, interior designer; and Matias, electrician), or both members were equal leaders (electricity producers). In the interior designer pair, Sofia, who had better social skills, led the process in agreement with Julia. However, the builders' (Lauri, LD; and Matias) composition (see Figure S-5 in the online materials) indicated a similar process to that of the electricians: They needed more directed teacher support than the landscapers did. The difference between these pairs was that the landscapers had a clear leader: Eetu (LD). In the builders' group, Matias only interacted with the other mainstream students and Eetu (LD, landscapers), and it was not until the second "planning" session that the teacher noticed the need for intensified support and began to guide their roles more directly:

Teacher:How was your cooperation today?

Matias:Fairly bad. Weak.

Teacher:Why?

Matias:Maybe Lauri [LD] wasn't so active. 
Teacher:Ok. What should you do next time? Lauri, you have been absent; you didn't know what to do [...] What could you do so that both of you know what to do? Matias:Maybe I could give instructions to Lauri.

Teacher:[...] You could ask "How are we going to share tasks today?" Then it would be nicer to cooperate. Right?

In the next session, first "creating" session, the teacher made sure that the builders divided their tasks and began to work immediately. The teacher also encouraged Lauri (LD), and they succeeded in the second "creating" session. However, after the third "creating" session, the teacher directed Lauri (LD), who did nothing: "I was really amazed that you just sat there, because you are seriously super good at crafts. This task is supposed to be done together. If the cooperation is so hard, you have to make deals together." The builders' process reveals the importance of concentrating on one's closest partner from the beginning of the project. This is beneficial to the entire process. The builders required more support and modelling for cooperation than the other pairs did. Lauri's (LD) absence in the first "planning" session might have prolonged the builders' cooperation. There might also have been other barriers to discourse at the beginning of the project that did not reveal themselves in the data. However, in the final 2 sessions, the need for teacher support diminished, and the builders found a way to cooperate and complete their sub-project together.

\section{Discussion}

The present case study reported a maker-centered PBL project that included elements of "learning by making" and differentiated instruction. The aim of our study was to explore how teacher-directed reflective discussions supported students' cooperation, promoted student participation, and helped with the construction of a scale-model house in different phases of maker-centered PBL. The present article emphasized the role of teacher-directed reflective discussions in improving students' cooperation skills and promoting inclusion-related participation. Facilitating cooperation and engaging students in supporting each other is evidently the most significant aspect of PBL that a teacher should focus on. With reflective discussions, the teacher can also promote students' competence building (Binkley et al., 2012). In the scale-model house project, discussions with the teacher influenced cooperation and social interaction between students with and without LD. The findings indicated that LD students were not segregated by other students, as is often the case (cf. Cohen, 1994; Pijl \& Frostad, 2010). However, some LD students chose to step aside in socially challenging sessions (e.g. planning). Even though LD students were less active in the team sessions, the organization of sub-projects seemed to support their participation in the project. The sub-projects provided both the structure that the LD students required and space for competence building. Previous studies have indicated that hands-on learning and investigations in science lessons are beneficial for LD students (cf. Bell, 2002; Lee \& So, 2015). Our study enriches the research concerning PBL by using Martinez and Stager's (2013) "learning by making" concept and providing structuration from Tomlinson's (1999) work on differentiated instruction. We have shown that learning in science can be facilitated in heterogeneous classes when students are able to learn the 
related disciplines, skills, and competences in a more in-depth way. However, more studies in similarly complex learning situations with related maker-centered projects and support strategies are needed.

Similar to inclusion, the implementation of PBL in terms of making, cooperation, and differentiation is not always straightforward; thus, teachers need examples of beneficial approaches, detailed illustrations, and models of good practice (cf. Jenkins et al., 2003; Pesonen et al., 2014). In Jenkins et al.'s (2003) study, teachers reported making minimal adjustments for LD students in cooperative activities that focused on group composition. They also reported that process support was lacking or varied. In this study, we differentiated project through engaging with shared artifacts and differentiated contents, processes, and products (Tomlinson, 1999). The content and product were considered when teachers were constructing the PBL unit, preparing the project, and making sure that all the students could fully participate. Recent studies have proven that group composition and the content of sub-projects prepare teachers for process differentiation (cf. Cohen, 1994; Tomlinson, 1999). It enables teachers to identify students' abilities and the group's social condition. It also helps teachers to identify students who will need differentiation during the process and intensified support in the reflective discussions. In this study, the reflective discussions were important for all students when cooperating at the beginning of the project, for some students in the planning and creating phases, and for some pairs in terms of their cooperation. Naturally, the LD students needed more personalized mentoring, but most of the pairs were able to take others into account following their first reflective discussion with the teacher. This research clarified that reflective discussions can be seen as models for student behavior and coordination in groups. We did not collect research data on teacher's actions in the class, but we assume that regular reflective discussions deepened self-knowledge and promoted competence building. For teachers in the field of education, the project provides an applicable example of how to construct an inclusive and maker-centered PBL unit and support student cooperation with regular reflective discussions. In Finland, interdisciplinary learning projects, similar to the project described in this paper, are part of the Finnish National Curriculum. However, in-service teacher training, both in Finland and other countries, could benefit from long-lasting maker-centered PBL courses in which practitioners deepen their knowledge of designing, implementing, and supporting interdisciplinary projects. Similar courses could also be beneficial for teacher preparation. The framework of the Finnish curriculum could also provide examples for curriculum developers in other countries.

We acknowledge that there are limitations to this study in terms of the uniqueness of the inclusive classroom setting and the diversity of the participating students. We recognize that conducting the study in a different school with different students could result in different outcomes due to individual differences and preferences. As well as this, the inclusive practices used in the class prior to the study period had further promoted student learning. Despite these limitations, the findings can be used to highlight the benefits of reflective discussions in supporting student participation. Engaging and challenging maker projects should be made available for all students, as it is necessary for future citizens to know how to work with different people of different abilities and interests so as to enhance a wide variety of competences and strengthen their sense of belonging (Binkley et al., 2012; Hick et al., 2009; UNESCO, 1994). 
Funding Details. This material is based upon work supported by the Academy of Finland grants 286837 and 294228 and Strategic Research Council grant 312527.

Funding Information Open access funding provided by University of Helsinki including Helsinki University Central Hospital.

\section{Compliance with Ethical Standards}

Conflict of Interest The authors declare that they have no conflict of interest.

Disclaimer The opinions expressed here are those of the authors and do not represent the views of the funding agencies.

Open Access This article is distributed under the terms of the Creative Commons Attribution 4.0 International License (http://creativecommons.org/licenses/by/4.0/), which permits unrestricted use, distribution, and reproduction in any medium, provided you give appropriate credit to the original author(s) and the source, provide a link to the Creative Commons license, and indicate if changes were made.

\section{References}

Alper, M. (2013). Making space in the makerspace: Building a mixed-ability maker culture. Interaction Design and Children Conference, June 24-27, 2013, New York, NY, USA.

Anderson, D., Thomas, G. P., \& Nashon, S. M. (2008). Social barriers to meaningful engagement in biology field trip group work. Science Education, 93(3), 511-534.

Bastian, M., Heymann, S., \& Jacomy, M. (2009). Gephi: An open source software for exploring and manipulating networks. International AAAI Conference on Weblogs and Social Media.

Bell, D. (2002). Making science inclusive: Providing effective learning opportunities for children with learning difficulties. Support for Learning, 17(4), 156-161.

Binkley, M., Erstad, O., Herman, J., Raizen, S., Ripley, M., Miller-Ricci, M., \& Rumble, M. (2012). Defining twenty-first century skills. In P. Griffin, B. McGaw, \& E. Care (Eds.), Assessment and teaching of 21st century skills (Vol. 1, pp. 17-66). Netherlands: Springer.

Blumenfeld, P. C., Soloway, E., Marx, R. W., Krajcik, J. S., Guzdial, M., \& Palincsar, A. (1991). Motivating projectbased learning: Sustaining the doing, supporting the learning. Educational Psychologist, 26(3-4), 369-398.

Brigham, F. J., Scruggs, T. E., \& Mastropieri, M. A. (2011). Science education and students with learning disabilities. Learning Disabilities Research and Practice, 26(4), 223-232.

Cohen, E. G. (1994). Restructuring the classroom: Conditions for productive small groups. Review of Educational Research, 64(1), 1-35.

Cook, B. G., \& Schirmer, B. R. (2003). What is special about special education: Overview and analysis. Journal of Special Education, 37(3), 200-205.

Esmonde, I. (2009). Ideas and identities: Supporting equity in cooperative mathematics learning. Review of Educational Research, 79(2), 1008-1043.

Finnish National Agency of Education. (2016). The Finnish core curriculum for basic education 2014. The Finnish National Board of Education. Retrieved July 5, 2018 from https://www.oph.fi/english/curricula and qualifications/basic education

Gómez Puente, S. M., van Eijck, M., \& Jochems, W. (2013). Facilitating the learning process in design-based learning practices: An investigation of teachers' actions in supervising students. Research in Science \& Technology Education, 31(3), 288-307. https://doi.org/10.1080/02635143.2013.837043.

Halinen, I., \& Järvinen, R. (2008). Towards inclusive education: The case of Finland. Prospects, 38, 77-97.

Hick, P., Kershner, R., \& Farrell, P. T. (Eds.). (2009). Psychology for inclusive education: New directions in theory and practice. London, England: Routledge.

Jacomy, M., Heymann, S., Venturini, T., \& Bastian, M. (2012). Force Atlas 2, a graph layout algorithm for handy network visualization. Retrieved June 12, 2018 from https://medialab.sciencespo. fr/publications/Jacomy_Heymann_Venturini-Force_Atlas2.pdf 
Jenkins, J. R., Antil, L. R., Wayne, S. K., \& Vadasy, P. F. (2003). How cooperative learning works for special education and remedial students. Exceptional Children, 69(3), 279-292.

Johnson, D. W., \& Johnson, F. P. (2013). Joining together: Group theory and group skills (5th ed.). New Jersey: Pearson.

Krajcik, J., \& Shin, N. (2015). Project-based learning. In K. Sawyer (Ed.), The Cambridge handbook of the learning sciences (2nd ed., pp. 275-297). New York, NY: Cambridge University Press.

Krajick, J., \& Merritt, J. (2012). Engaging students in scientific practices: What does constructing and revising models look like in the science classroom? Understanding a framework for K-12 science education. The Science Teacher, 79(3), 38-41.

Lee, T. T. H., \& So, W. W. M. (2015). Inquiry learning in a special education setting: Managing the cognitive loads of intellectually disabled students. European Journal of Special Needs Education, 30(2), 156-172.

Martinez, S. L., \& Stager, G. S. (2013). Invent to learn: Making, tinkering, and engineering in the classroom. Torrance, CA: Constructing Modern Knowledge Press.

Niilo Mäki Instituutti. (2015). Clinic for learning difficulties. Retrieved from http://www.nmi. fi/en/lastentutkimusklinikka-en.

Pesonen, H., Itkonen, T., Jahnukainen, M., Kontu, E., Kokko, T., Ojala, T., \& Pirttimaa, R. (2015). The implementation of new special education legislation in Finland. Educational Policy, 29(1), 162-178.

Pijl, S. J., \& Frostad, P. (2010). Peer acceptance and self-concept of students with disabilities in regular education. European Journal of Special Needs Education, 25(1), 93-105.

Stake, R. (2005). Qualitative case studies. In N. Denzin \& Y. Lincoln (Eds.), The SAGE handbook of qualitative research (3rd ed., pp. 443-466). Thousand Oaks, CA: Sage.

Stalker, K. (1998). Some ethical and methodological issues in research with people with learning difficulties. Disability \& Society, 13(1), 5-19.

Stamovlasis, D., Dimos, A., \& Tsaparlis, G. (2006). A study of group interactions processes in learning lower secondary physics. Journal of Research in Science Teaching, 43(6), 556-576.

Sullivan, F. R., \& Wilson, N. C. (2015). Playful talk: Negotiating opportunities to learn in collaborative groups. The Journal of Learning Sciences, 24(1), 5-52.

The Finnish Basic Education Act 642 (2010). Retrieved July 5, 2018 https:/www.finlex.fi/en/laki/kaannokset/1998 /en19980628.pdf

Tomlinson, C.A. (1999). The differentiated classroom: Responding to the needs of all learners [Kindle edition]. Retrieved October 20, 2013 from Amazon.com.

Tomlinson, C. A., Brighton, C., Hertberg, H., Callahan, C. M., Moon, T. R., Brimijoin, K., Conover, L. A., \& Reynolds, T. (2003). Differentiating instruction in response to student readiness, interest, and learning profile in academically diverse classrooms: A review of literature. Journal of the Education of the Gifted, 27(2/3), 119-145.

United Nations Educational, Scientific and Cultural Organization. (1994). The Salamanca Statement and Framework for Action on Special Needs Education. Paris, France: Author.

van de Pol, J., Volman, M., Oort, F., \& Beishuizen, J. (2014). Teacher scaffolding in small-group work: An intervention study. The Journal of the Learning Sciences, 23(4), 600-650.

Webb, N. M., Nemer, K. M., Chizhik, A. W., \& Sugrue, B. (1998). Equity issues in collaborative group assessment: Group composition and performance. American Educational Research Journal, 35(4), $607-651$.

\section{Affiliations}

\section{Kati Sormunen ${ }^{1} \cdot$ Kalle Juuti $^{1}$ - Jari Lavonen ${ }^{1,2}$}

Kati Sormunen

kati.sormunen@helsinki.fi

1 Faculty of Educational Sciences, University of Helsinki, Siltavuorenpenger 5A, PL 9, 00014 Helsinki, Finland

2 Department of Childhood Education and Centre for Education Practice Research, University of Johannesburg, Soweto, South Africa 